\title{
Refining uptake and depuration constants for fluoroalkyl chemicals in Chironomus riparius larvae on the basis of experimental results and modelling
}

Delphine Bertin ${ }^{\mathrm{a}}$, Benoît J. D. Ferrari ${ }^{\mathrm{a}, \mathrm{b}}$, Pierre Labadie ${ }^{\mathrm{c}}$, Alexandre Sapin ${ }^{\mathrm{a}}$, Débora Da Silva Avelar $^{\mathrm{a}}$, Rémy Beaudouin ${ }^{\mathrm{d}}$, Alexandre Péry ${ }^{\mathrm{e}, \mathrm{f}}$, Jeanne Garric ${ }^{\mathrm{a}}$, Hélène Budzinski ${ }^{\mathrm{c}}$, Marc Babut $^{\mathrm{a} *}$

a IRSTEA, UR MALY, 5 rue de la Doua, BP 32108, F- 69616 Villeurbanne, France;

${ }^{\mathrm{b}}$ Swiss Centre for Applied Ecotoxicology Eawag-EPFL (CentreEcotox), EPFL-ENAC-IIEGE, Station 2, CH-1015 Lausanne, Switzerland;

${ }^{\mathrm{c}}$ CNRS, UMR 5805 EPOC (LPTC Research group), Université de Bordeaux, 351 Cours de la Libération, F-33405 TALENCE, France;

${ }^{\text {d } U n i t e ́ ~ M o d e ̀ l e s ~ p o u r ~ l ' E c o t o x i c o l o g i e ~ e t ~ l a ~ T o x i c o l o g i e ~(M E T O), ~ I n s t i t u t ~ N a t i o n a l ~ d e ~}$ l'Environnement Industriel et des Risques (INERIS), BP2, F-60550 Verneuil en Halatte, France

e AgroParisTech, UMR 1402 INRA-AgroParisTech EcoSys, F-78850 THIVERVALGRIGNON, France

f INRA, UMR 1402 INRA-AgroParisTech EcoSys, F-78850 THIVERVAL-GRIGNON, France

Present addresses

- Delphine Bertin, UMR 5023 LEHNA (E3S Research group), Université ClaudeBernard Lyon 1, 6 rue Raphaël Dubois, 69622 Villeurbanne, Cedex, France delphine.bertin@univ-lyon1.fr

- Débora Da Silva Avelar: dhezinha@gmail.com

- Alexandre Sapin - Rovaltain Research Company BP 10 313, F-26958 Valence cedex 9, France; asapin@ rovaltainresearch.com 
Role of the funding source

The laboratory experiments and analyses were mainly funded by the Rhone-Mediterranean and Corsica Water Agency and the Rhône-Alps Region within the Rhône ecological restoration plan. Additional grants were obtained from the Aquitaine Region and the European Union (CPER A2E project), and the French National Research Agency (ANR) as part of the Investments for the Future Program, within the Cluster of Excellence COTE (ANR-10-LABX-45). None of these supports were involved in the study design, nor in data processing, report writing and article submission. 


\section{Highlights}

- Chironomids were exposed to sediment contaminated by fluoro-alkyl substances.

- For all compounds, nearly complete elimination from tissues was achieved in $42 \mathrm{~h}$.

- Modeling shows that PFTrDA uptake is concentration-dependent.

\section{Abstract}

The aims of this study were to determine depuration rates for a range of per- and polyfluoroalkyl substances (PFASs) using Chironomus riparius, and to test a concentrationdependency hypothesis for the long-chain perfluorotridecanoic acid (PFTrDA) for this species. Midge larvae were exposed to field sediments collected downstream of a fluorotelomer plant, and to the same sediment spiked with PFTrDA. Elimination kinetics results indicated complete elimination of all PFASs by chironomids after $42 \mathrm{~h}$. These data were used to develop two PFTrDA bioaccumulation models accounting for chironomid growth and for compound concentration dependency or not. There was much better agreement between observed and simulated data under the concentration-dependency hypothesis than under the alternative one (passive diffusion). The PFTrDA uptake rate derived from the concentration-dependency model equaled $0.013 \pm 0.008 \mathrm{~g}_{\mathrm{oc}} \cdot \mathrm{g}_{\mathrm{ww}} \cdot \mathrm{h}^{-1}$, and the depuration rate $0.032 \pm 0.009 \mathrm{~h}^{-1}$

\section{Keywords}

Per- and polyfluoroalkyl substances; perfluorotridecanoic acid; Chironomus riparius; bioaccumulation; uptake rate; concentration-dependency

\section{Introduction}

Perfluoroalkyl and polyfluoroalkyl substances (PFASs) are compounds of emerging interest; their numerous uses and specific properties induce their global distribution in the environment (Houde et al., 2011; Houde et al., 2006; Prevedouros et al., 2006). The physicochemical 
properties of PFASs differ substantially from those of other persistent organic pollutants (POPs). While the perfluoroalkyl moiety is hydrophobic and lipophobic (Bhhatarai and Gramatica, 2011), the functional group increases the solubility in water, and per- and polyfluoroalkyl acids are thus amphiphilic. These complex properties make it difficult to predict their bioaccumulation, even though it seems that the bioaccumulation of longer-chain PFASs is partly driven by their increasing lipophilic character (Greaves et al., 2013). Several studies have shown the presence of PFASs in sediment (Ahrens et al., 2009; Bao et al., 2009; Bao et al., 2010; Higgins et al., 2005; Labadie and Chevreuil, 2011; Myers et al., 2012; Zushi et al., 2010), whereas other studies have suggested the importance of sediment as a PFAS source for biota (e.g., Martin et al., 2004). However, PFAS transfer from sediment to biota is poorly understood. Only a few experimental studies have provided evidence of bioaccumulation from sediment by benthic invertebrates, namely in the oligochaete worm, Lumbriculus variegatus (Higgins et al., 2007; Lasier et al., 2011; Prosser et al., 2016), in insect Chironomus riparius (Bertin et al., 2014) and Hexagenia spp. larvae (Prosser et al., 2016), and in an amphipod, Gammarus spp. (Bertin et al., 2016). Two contamination routes were identified for C. riparius: food was the main route of exposure for perfluorinated carboxylic acids (PFCAs) with a fluorinated chain from $\mathrm{C}_{11}$ to $\mathrm{C}_{14}$, and perfluorooctane sulfonamide (FOSA). For perfluoroundecanoic acid (PFUnDA), perfluorooctane sulfonate (PFOS), and 6:2 fluorotelomer sulfonic acid (6:2 FTSA), which are present in pore water (PW) and sediment, both uptake from water (i.e. respiration) and from food were involved. Accumulated concentrations in this species fit an exponential curve which could be supported by two models: (i) a classical partition model (Higgins et al., 2007), which assumes that the PFASs concentrations in organisms and sediment at steady state are proportional; and (ii) a concentration-dependency model (Liu et al., 2011), which hypothesizes that the uptake kinetics involves active transport through binding to specific sorption sites, such that these 
sites may become saturated at high exposure concentrations. To gain a more accurate understanding of the processes underpinning the PFAS uptake mechanisms for chironomids, and to refine the uptake and depuration constants, the models proposed must be tested to determine which is the most suitable.

The aims of the present study were therefore (i) to describe PFAS elimination kinetics for chironomids, and (ii) to test the concentration dependency of the PFAS bioaccumulation for a model compound, the perfluorotridecanoic acid (PFTrDA). A combined accumulation and depuration experiment involving field sediment was implemented to address the first objective. For the second one, we conducted combined accumulation and depuration experiments at different concentrations and applied a bioaccumulation model adapted to these compounds and species that could account for realistic kinetics constants.

\section{Bioaccumulation modeling: theoretical background}

Assuming that PFAS uptake and elimination depend on the organisms' surface, the dynamics of the PFAS load in the organism are defined as follows:

$\frac{d\left(Q_{\text {org }}\right)}{d t}=S_{\text {org }} \cdot k_{u} \cdot C_{\text {sed }-o c}-S_{\text {org }} \cdot k_{e} \cdot C_{\text {org }}$

where $Q_{\text {org }}$ corresponds to the quantity of PFASs in and/or on the organism, $S_{\text {org }}$ the chironomids surface, $k_{u}\left(\mathrm{~g} \cdot \mathrm{g}_{\mathrm{ww}} \cdot \mathrm{mm}^{-2} \cdot \mathrm{d}^{-1}\right)$ and $k_{e}\left(\mathrm{~mm}^{-2} \cdot \mathrm{d}^{-1}\right)$ the uptake and elimination constants, respectively. $C_{\text {sed-oc }}$ (ng. $\mathrm{g}_{\mathrm{oc}}{ }_{\mathrm{dw}}^{-1}$ ) and $C_{\text {org }}\left(\mathrm{ng} \cdot \mathrm{g}^{-1}\right.$ ww) indicate the PFAS concentrations in sediment adjusted to the $f_{o c}$, and in the organisms, respectively. As a consequence of growth during the test (Péry et al., 2002), the tissue concentration dynamics is described by Eq. 2 (details in SI):

$$
\frac{d\left(C_{\text {org }}\right)}{d t}=\left(\frac{1}{L} \cdot k_{u} \cdot C_{\text {sed }-o c}-\frac{1}{L} \cdot k_{e} \cdot C_{\text {org }}\right)-C_{\text {org }} \times \frac{d(V)}{d t} \times \frac{1}{V}
$$


73

$$
S=\frac{1}{\left({ }_{1+}{ }^{\operatorname{Corg}} / C_{50}\right)}
$$

\subsection{Chemicals}

chironomid volume $\left(\mathrm{cm}^{3}\right)$. Note that $k_{u}$ and $k_{e}$ in Eq. (2) are expressed in different units than in Eq. (1), namely goc. $\mathrm{g}_{\mathrm{ww}} \cdot \mathrm{h}^{-1}$ for $k_{u}$ and $\mathrm{h}^{-1}$ for $k_{e}$.

PFAS uptake may or may not be concentration-dependent, i.e. this uptake could follow either first order kinetics or kinetics with saturation. In case of concentration-dependency, the accumulation can be viewed as an adsorption-like process, in which the chemical adsorb at binding sites, i.e. specific components of the organs where PFASs accumulate (Liu et al., 2011). The binding site saturation process progressively slows down the uptake, and the steady state is reached at a lower concentration than in the case of a first order kinetics. Both the concentration in the exposure media and the number of sites remaining free control the uptake rate. The $S$ term was introduced in order to model these two cases:

with $C_{50}$ representing the half-saturation concentration, i.e. the internal concentration at which the uptake is one-half of its maximum rate. When $C_{\text {org }}$ is low, $S$ is close to 1 , and the dynamics follow Eq. 2; conversely, when $C_{\text {org }}$ increases and site binding occurs, $S$ decreases and tends to 0 , meaning that the uptake is lower or stopped. The final equation is:

$\frac{d\left(C_{\text {org }}\right)}{d t}=\left(\frac{1}{L} \cdot k_{u} \cdot C_{\text {sed }-o c} \cdot S-\frac{1}{L} \cdot k_{e} \cdot C_{\text {org }}\right)-C_{\text {org }} \times \frac{d(V)}{d t} \times \frac{1}{V}$

A half-life $\left(T_{1 / 2}\right)$ can be derived from the model as the time necessary for a $50 \%$ decrease in the accumulated concentration.

\section{Materials and Methods}

Standard PFAS solutions (PFC-MXA and PFS-MXA) were obtained from Wellington Laboratories (via BCP Instruments, Irigny, France): PFC-MXA contained perfluoro-n- 
butanoic acid (PFBA), perfluoro-n-pentanoic acid (PFPA), perfluoro-n-hexanoic acid (PFHxA), perfluoro-n-heptanoic acid (PFHpA), perfluoro-n-octanoic acid (PFOA), perfluoron-nonanoic acid (PFNA), perfluoro-n-decanoic acid (PFDA), perfluoro-n-undecanoic acid (PFUnDA), perfluoro-n-dodecanoic acid (PFDoDA), perfluoro-n-tridecanoic acid (PFTrDA), and perfluoro-n-tetradecanoic acid (PFTeDA), each at 2 ng. $\mu \mathrm{L}^{-1}$ in methanol (MeOH). PFSMXA contained perfluoro-1-butanesulfonate (PFBS) potassium salt, perfluoro-1hexanesulfonate PFHxS) sodium salt, perfluoro-1-heptanesulfonate (PFHpS) sodium salt, nperfluoro-1-octanesulfonate (PFOS) sodium salt and perfluoro-1-decanesulfonate (PFDS) sodium salt, N-Ethyl perfluorooctane sulfonamide (EtFOSA), N-Methyl perfluorooctane sulfonamide (MeFOSA), perflurooctane sulfonamide (FOSA), N-Ethyl perfluorooctane sulfonamidoacetic acid (EtFOSAA), N-Methyl perfluorooctane sulfonamidoacetic acid (MeFOSAA), and 6:2 Fluorotelomer sulfonic acid (6:2 FTSA), each at 2 ng. $\mu \mathrm{L}-1$ in $\mathrm{MeOH}$. A working solution containing all analytes, each at approximately $0.05 \mathrm{ng} . \mu \mathrm{L}^{-1}$, was prepared in $\mathrm{MeOH}$ and stored at $-18^{\circ} \mathrm{C} .{ }^{13} \mathrm{C}$-labelled perfluorodecanoic acid (PFDA), PFOS, and perfluorooctane sulfonamide (FOSA), each at $50 \mathrm{ng} \cdot \mu \mathrm{L}^{-1}$ in $\mathrm{MeOH}$, were supplied by Wellington Laboratories and used as internal standards (ISs). A working solution was prepared in $\mathrm{MeOH}$, each containing IS at $0.1 \mathrm{ng} \cdot \mu \mathrm{L}^{-1}$ (Table $\mathrm{S} 1$ in supplementary information).

LC/MS-grade $\mathrm{MeOH}$ and acetonitrile $(\mathrm{ACN})$ were purchased from J.T. Baker via Interchim (Montluçon, France). Sodium acetate buffer (99\%, ACS Reagent), ammonium hydroxide (28$30 \%$ in water), $0.2-\mu \mathrm{m}$ nylon centrifuge tube filters, and ENVI-Carb cartridges ( $6 \mathrm{cc}, 250 \mathrm{mg}$ ) were obtained from Sigma-Aldrich (St Quentin Fallavier, France), whereas Strata XAW (6 ml, $200 \mathrm{mg}$ ) were purchased from Phenomenex (Le Pecq, France). Nitrogen (99\%) was supplied by Air Liquide (Paris, France). Ultra-pure water was obtained using an Elix 10 purification system fitted with an EDS pack (Millipore, Guyancourt, France). 
Two experiments were conducted with $C$. riparius: an accumulation test with field and fieldspiked sediment, and an elimination test with field and field-spiked sediment (Figure S1 in SI). The decision to spike field sediment was made for testing the concentration-dependency hypothesis; spiking involved PFTrDA, the main PFAS among those detected in the field sediment used in the present study (Munoz et al., 2015). The elimination experiment was implemented in order to improve the accumulation kinetics modelling when concentrationdependency occurs (Bertin et al., 2014).

The study was conducted using sediment collected at Beurre Island (characteristics in SI). This site is a fluvial annex of the Rhone River (eastern central France,

Since 1902, this industrial site has been used to produce hydrofluoric acid and a wide array of fluorine-based organics. Three PFAS production periods can be defined at this site: (i) polytetrafluoroethylene (PTFE) production from 1960 to 1987, (ii) fluorinated copolymers synthesis from 1981 to 1996 , and (iii) polyvinylfluoridene (PVDF) production from $\approx 1981$ onwards (Dauchy et al., 2012). Two campaigns were conducted in 2013 (March and November): $50 \mathrm{~L}$ of surface sediments $(\approx 5 \mathrm{~cm}$ deep) were collected from the river bed with a Van-Veen grab, kept on ice, and brought to the laboratory, where they were sieved at $2 \mathrm{~mm}$, pooled in a polypropylene (PP) jar, and stored at $4{ }^{\circ} \mathrm{C}$.

\subsubsection{Sediment spiking}

141 In order to test the concentration-dependency hypothesis, field sediments were spiked with

142 PFTrDA, on the basis of the field sediment contamination pattern (Munoz et al., 2015), and 143 on the chironomids accumulation capacity (Bertin et al., 2014). The loss of ignition (LOI) 
values of these sediments laid between $5.2 \%$ and $5.4 \%$, corresponding to organic carbon fractions $\left(f_{o c}\right)$ of 0.02 (conversion factor of 2.4 based on Craft et al.,1991). The spiking solution was prepared with a stock solution purchased from Wellington Laboratories (via BCP Instruments, Irigny, France). For each concentration, a PFTrDA solution $\left(0.1\right.$ g.L $\mathrm{L}^{-1}$ in $\mathrm{MeOH}$ ) was added to $1.2 \mathrm{~L}$ of sediment and $0.4 \mathrm{~L}$ of clean water. The bottles were gently shaken for $6 \mathrm{~h}$; the sediment was then allowed to settle for $48 \mathrm{~h}$ and the overlying water (OW) cautiously siphoned off. The sediment was then homogenised and subsequently reintroduced in aquaria for chironomid exposure. In the first experiment, PFTrDA was added at twice (C1) its initial concentration in the field sediment $\left(1.64 \pm 0.03 \mathrm{ng} \cdot \mathrm{g}^{-1} \mathrm{dw}\right)$. The accumulation phase was reduced to 2 days, in order to increase the duration of the depuration period and get more samples for this phase. For a second experiment PFTrDA was added at approximately five times $(\mathrm{C} 2)$ the initial field sediment concentration $\left(1.67 \pm 0.48 \mathrm{ng} \cdot \mathrm{g}^{-1} \mathrm{dw}\right)$ and ten times $(\mathrm{C} 3)$ the field sediment concentration $\left(1.67 \pm 0.48 \mathrm{ng} \cdot \mathrm{g}^{-1} \mathrm{dw}\right)$. Note that two different batches of field sediments were used for these experiments, displaying similar PFTrDA concentrations at $1.64 \pm 0.03 \mathrm{ng} \cdot \mathrm{g}^{-1} \mathrm{dw}$ and $1.67 \pm 0.48 \mathrm{ng} \cdot \mathrm{g}^{-1} \mathrm{dw}$ (Table S2). Sediment depth after transfer in the aquaria was approximately $5 \mathrm{~cm}$.

\subsubsection{Chironomus riparius accumulation and depuration tests}

Chironomids were obtained from our laboratory cultures maintained according to standard methods (OECD, 2004; AFNOR, 2010). Experiments were conducted in the same laboratory conditions as previously described by Bertin et al. (2014). Briefly, C. riparius fourth instar (L4) larvae (7-day-old larvae post-hatching) were exposed to field sediment covered with OW, i.e., a mixture of groundwater and water purified by reverse osmosis, to reach a conductivity of $300 \mu \mathrm{S} . \mathrm{cm}^{-1}$. Each experiment was conducted at $21^{\circ} \mathrm{C}$ under a $16: 8-\mathrm{h}$ lightdark photoperiod. The OW was renewed four times per day to maintain adequate water quality and oxygenation. Ancillary parameters such as $\mathrm{pH}$, dissolved oxygen concentration, 
conductivity, $\mathrm{NO}_{2}^{-}$, and $\mathrm{NH}_{4}^{+}$were monitored.

\subsubsection{Accumulation test at several exposure concentrations}

Three aquaria $(38 \times 20 \times 24.5 \mathrm{~cm}$ in polystyrene) were prepared with $4 \mathrm{~L}$ of homogenized sediment and 15 L of OW: one with field sediment, one with C2-spiked sediment and the last one with C3-spiked sediment. Three control aquaria were prepared in parallel with silica sand (particle size distribution: $90 \% 50-200 \mu \mathrm{m}, 10 \%<50 \mu \mathrm{m}$ ). A total of $2400 \mathrm{~L} 4$ larvae were added to sediment and control aquaria (400 in each aquarium). After 4 days of exposure (Fig. S1- part A), chironomids from both test and control aquaria were collected and cryopreserved, as explained below in section 3.2.6.

\subsubsection{Elimination test}

Four more aquaria were prepared, each with $4 \mathrm{~L}$ of homogenized sediment spiked with PFTrDA (i.e. C1) with 15 L of OW. One control aquarium was prepared with silica sand having the same characteristics and origin as in the accumulation test. A total of ca. $4.000 \mathrm{~L} 4$ larvae were added to the spiked-sediment aquaria (1000 in each aquarium), and 400 L4 larvae were added to the control aquarium. After 2 days of exposure, up to 400 larvae were collected in the sediment; the larvae remaining in the spiked-sediment aquarium were directly (without gut clearance phase) transferred to three aquaria (400 larvae in each aquarium) containing silicate sand and clean water for the depuration phase. Similarly, 1.200 remaining larvae from the field sediment aquaria were directly (without gut clearance phase) transferred to three aquaria prepared with silica and clean water. The organisms were collected and sacrificed after $6 \mathrm{~h}, 18 \mathrm{~h}$, and $42 \mathrm{~h}$ of depuration (one aquarium stopped at each time); finally, $42 \mathrm{~h}$ after the transfer the control organisms were also sacrificed (Fig. S1 - part B).

The same design was applied to field (un-spiked) sediment.

\subsubsection{Sample collection and organism measurements}


The OW was sampled in 1-L polyethylene (PE) bottles and the pore water (PW) was sampled with a porous polymer micro-sampler (Rhizon ${ }^{\circledR}$ system, SDEC, Reignac-sur-Indre, France; description in SI). At the end of exposure, subsamples from sediment were deposited in PE tubes. Chironomids were collected by sieving sediment or silica at $500 \mu \mathrm{m}$; about 200 larvae (ca $800 \mathrm{mg} \mathrm{ww}$ or $200 \mathrm{mg} \mathrm{dw}$ ) were pooled and cryopreserved in liquid nitrogen and then stored at $-21^{\circ} \mathrm{C}$ before PFAS analysis. As C. riparius gut contents represent about $6 \%$ of the total body weight (Ferrari et al., 2014), and gut clearance was not feasible in the elimination test, organisms were directly sacrificed. Water and sediment samples were frozen and kept at $-21^{\circ} \mathrm{C}$. Additionally, initial body residue was determined by pooling and cryopreserving about 200 individuals at the start of each experiment.

Chironomid survival, length and (wet) weight were determined for each time point, including the start of each experiment. To determine the total length, four groups of ten larvae were photographed and the mean sizes determined using digital image analysis software (Jmicrovision, available free at http://www.jmicrovision.com/). The same groups were then weighed (weighing scales: Sartorius CPA225D, France) to obtain mean individual masses.

\subsection{PFAS analysis}

\subsubsection{PFAS extraction}

The PFAS extraction methods for OW, PW and sediment samples were similar to those described in Bertin et al. (2014). Briefly, PFASs were extracted from water samples using Phenomenex Strata-XAW cartridges while sonication in methanol was used for sediment samples, followed by graphitized carbon black clean-up. For the chironomid samples, the method was adapted with minor modifications: both neutral and acid analytes were eluted in a single fraction using $\mathrm{MeOH}$ containing $0.2 \% \mathrm{NH}_{4} \mathrm{OH}\left(30 \%\right.$ in water). ${ }^{13} \mathrm{C}$-labeled PFAS internal standards (ISs) were added before the extraction. PFASs were analyzed on freezedried tissues based on $800 \mathrm{mg}$ wet weight (ww) for C. riparius and $120 \mathrm{mg}$ dry weight for the 
SRM 1947 fish reference matrix(Reiner et al., 2012).

\subsubsection{LC-MS/MS analysis}

PFASs were analysed using an Agilent 1200 LC system (Agilent Technologies, Massy, France) interfaced with an Agilent 6460 triple quadrupole mass spectrometer (details in Table S3).

\subsubsection{Quality control and methods}

Analyte recovery was determined using spiked samples $(n=3)$ for each matrix (surface and pore water, sediment, and chironomids) within the range $50-123 \%$ (Table S4).

Replicate procedural blanks were analysed for each series of samples. PFAS concentrations were blank-corrected when applicable. For compounds present in blanks, the limits of detection (LDs) were defined as three times the standard deviation of the blank, and the limits of quantification (LQs) were set at ten times the standard deviation of the blank. For analytes not detected in the blanks, LDs $\left(0.001-0.103 \mathrm{ng} . \mathrm{g}^{-1}\right.$ or ng. $\left.\mathrm{L}^{-1}\right)$ and LQs $\left(0.003-0.310 \mathrm{ng}^{-\mathrm{g}^{-1}}\right.$ or ng. $\mathrm{L}^{-1}$ ) were determined as the concentration with a signal-to-noise ratio of 3 and 9 ,

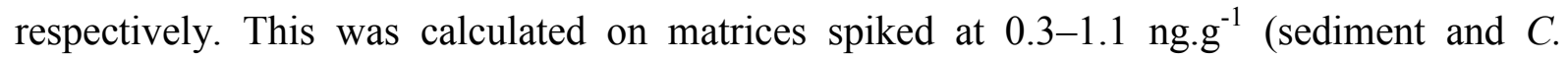
riparius) and $0.7-1.4$ ng. $\mathrm{L}^{-1}$ (Vittel ${ }^{\circledR}$ mineral water samples) (Table S5). The PFASs measured in SRM 1947 Lake Michigan Fish Tissue and compared with the NIST value are presented in SI (Table S6).

\subsection{Data analyses and modelling}

Data were checked for normality using the Shapiro-Wilk test and were analysed using the Student $t$-test. Experimental biota-to-sediment accumulation factors $\left(B S A F_{\text {exp }}\right)$ were determined by dividing tissue concentrations $\left(C_{\text {org }}, \mathrm{ng} . \mathrm{g}^{-1} \mathrm{ww}\right)$ at steady state by concentrations in sediment normalized by $f_{o c}\left(C_{s e d-o c}=\mathrm{C}_{\text {sed }} / f_{o c}\right.$ ng.g $\left.\mathrm{goc}^{-1} \mathrm{dw}\right)$ (Ankley, 1992; Burkhard et al., 2012). As lipids do not influence PFAS accumulation in tissues, it is not 
appropriate to adjust $C_{\text {org }}$ to chironomid lipid content (Higgins et al., 2007).

243 Concerning the bioaccumulation modelling, two different hypotheses were tested: $(H 1)$ concentration dependency (Eq. 4), and (H2) no concentration-dependency (Eq. 2). The model parameter values (depending on the hypothesis) were adjusted simultaneously in order to obtain the best fit to experimental data. The uptake and elimination coefficient $\left(k_{u}\right.$ and $\left.k_{e}\right)$, the half-saturation concentration $\left(C_{50}\right)$ and the growth rate $(r)$ were adjusted simultaneously by minimizing the weighted least squares between the simulated and observed data. For each hypothesis, the distance and the adjusted coefficient of determination $\left(\mathrm{R}^{2}\right)$ were calculated.

Model calculations and data analyses were performed with R software (R-Core-team, 2012) within the RStudio environment (Version 0.97.336).

\section{Results}

\subsection{Sediment contamination}

Long chain perfluoro-alkyl carboxylates were predominant in field sediments: PFUnDA (0.85 \pm 0.11 ng.g dw ${ }^{-1}$ and $0.91 \pm 0.26$ ng. $\left.\mathrm{g}^{-1} \mathrm{dw}\right)$ and PFTrDA $\left(1.64 \pm 0.03 \mathrm{ng} \cdot \mathrm{g} \mathrm{dw}^{-1}\right.$ and $1.67 \pm$ 0.48 ng. $\left.\mathrm{g}^{-1} \mathrm{dw}\right)$ in March and November respectively. PFOS $\left(0.58 \pm 0.05 \mathrm{ng} . \mathrm{g} \mathrm{dw}^{-1}\right.$ and $0.36 \pm$ 0.13 ng. $\left.\mathrm{g}^{-1} \mathrm{dw}\right)$ and FOSA $\left(0.03 \pm 0.01 \mathrm{ng} \cdot \mathrm{g} \mathrm{dw}^{-1}\right.$ and $\left.0.045 \pm 0.02 \mathrm{ng} . \mathrm{g} \mathrm{dw}^{-1}\right)$ were observed at much lower concentrations. PFTrDA strongly sorbed onto sediment particles and its concentration increased with the increasing spiking level: after spiking the measured PFTrDA were $3.66 \pm 0.48 \mathrm{ng} \cdot \mathrm{g}^{-1} \mathrm{dw}(\mathrm{C} 1) ; 5.83 \pm 0.72 \mathrm{ng} \cdot \mathrm{g}^{-1} \mathrm{dw}(\mathrm{C} 2) ; 10.78 \pm 0.64 \mathrm{ng} \cdot \mathrm{g}^{-1} \mathrm{dw}(\mathrm{C} 3)$

(Fig.S2; Table S7). PFTrDA concentrations apparently decreased during the tests by $43 \%$ in one instance $(\mathrm{C} 2)$; they might have decreased slightly in the other instances, by about $10 \%$ (field, C3), to $25 \%$ (field) (Table S6 in SI), so within the range of the analytical uncertainty. 
$96.0 \%$ for the test samples (field sediment, $C 2$, and $C 3$, respectively) and $97.1 \pm 2.9 \%$ for the $\pm 17.7 \%$ for the test and $81.9 \%$ and $91.1 \pm 4.0 \%$ for the control samples, respectively. The larva length data fit a linear growth model well $\left(\mathrm{R}^{2}=0.798\right)$.

Concentrations in control treatments were systematically below LDs. The chironomids 271 accumulated two PFCAs (PFUnDA and PFTrDA) as well as PFOS and its precursor FOSA

272 (Figure 1). For all compounds, PFAS elimination was nearly complete in $42 \mathrm{~h}$.

Figure 1: Elimination kinetics of PFASs in chironomids exposed to field sediment (unspiked: black; spiked: open symbols) for each PFAS. Error bars correspond to the analytical uncertainty.
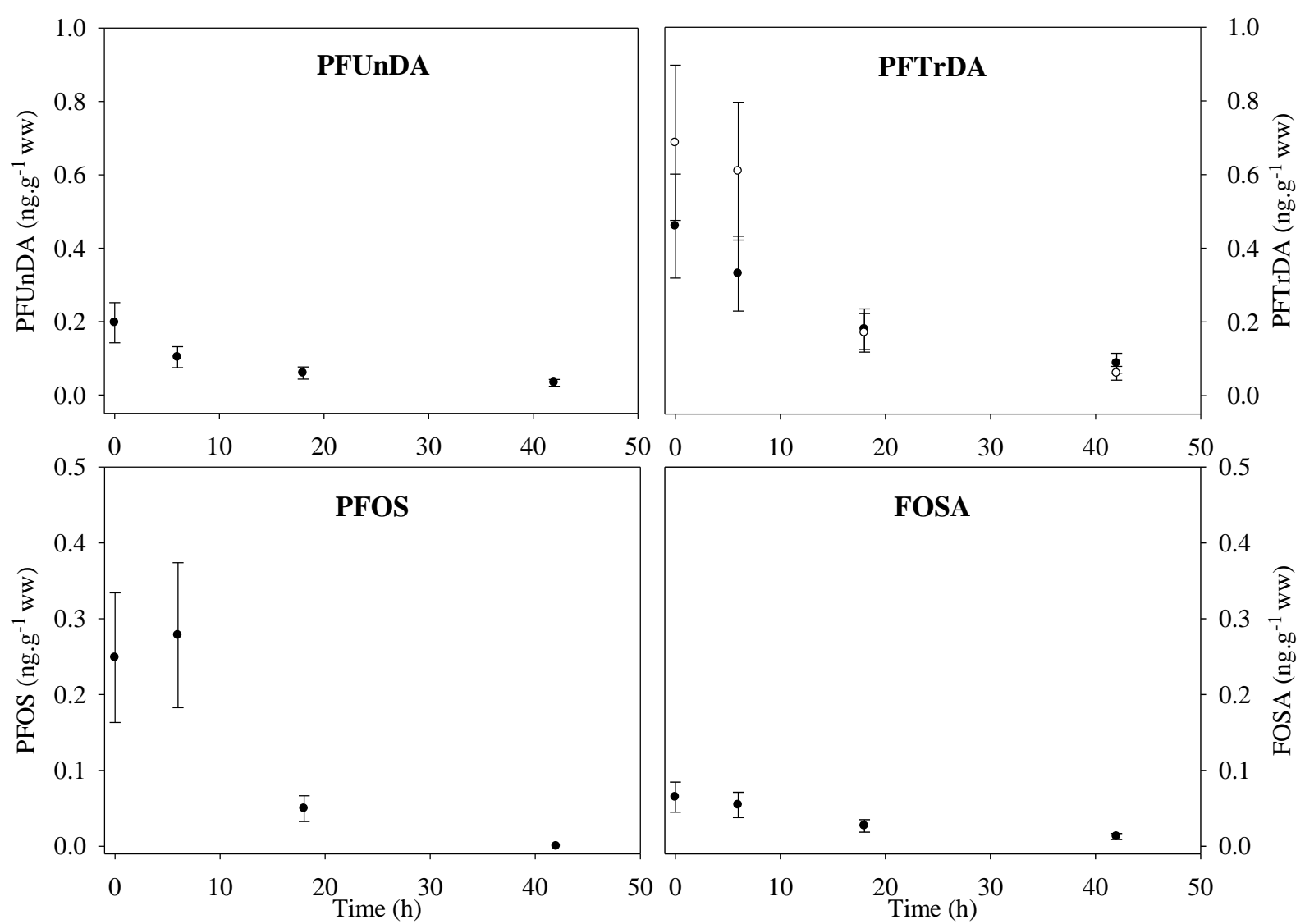

In all these experiments, the PFTrDA concentration increase in spiked sediments was more important than in chironomids (Figure 2): while the raw sediment concentration increased by 
a factor $\approx 2-3$ in $(\mathrm{C} 2)$ and $\approx 6(\mathrm{C} 3)$, the respective increase rates in chironomids were $\approx 1.5$

(C1), $3.4(\mathrm{C} 2)$ and $5.6(\mathrm{C} 3)$. This pattern was more evident when PFTrDA concentrations in sediment were adjusted to organic carbon content (Table 1).

282

Figure 2: Biplot of PFTrDA concentrations in sediment (X-axis) and C. riparius (Y-axis); error bars account for the analytical uncertainty; open squares: November field sediment and related spiked sediment (C1); gray dots: March field sediment and related spiked sediments $(\mathrm{C} 2, \mathrm{C} 3)$.

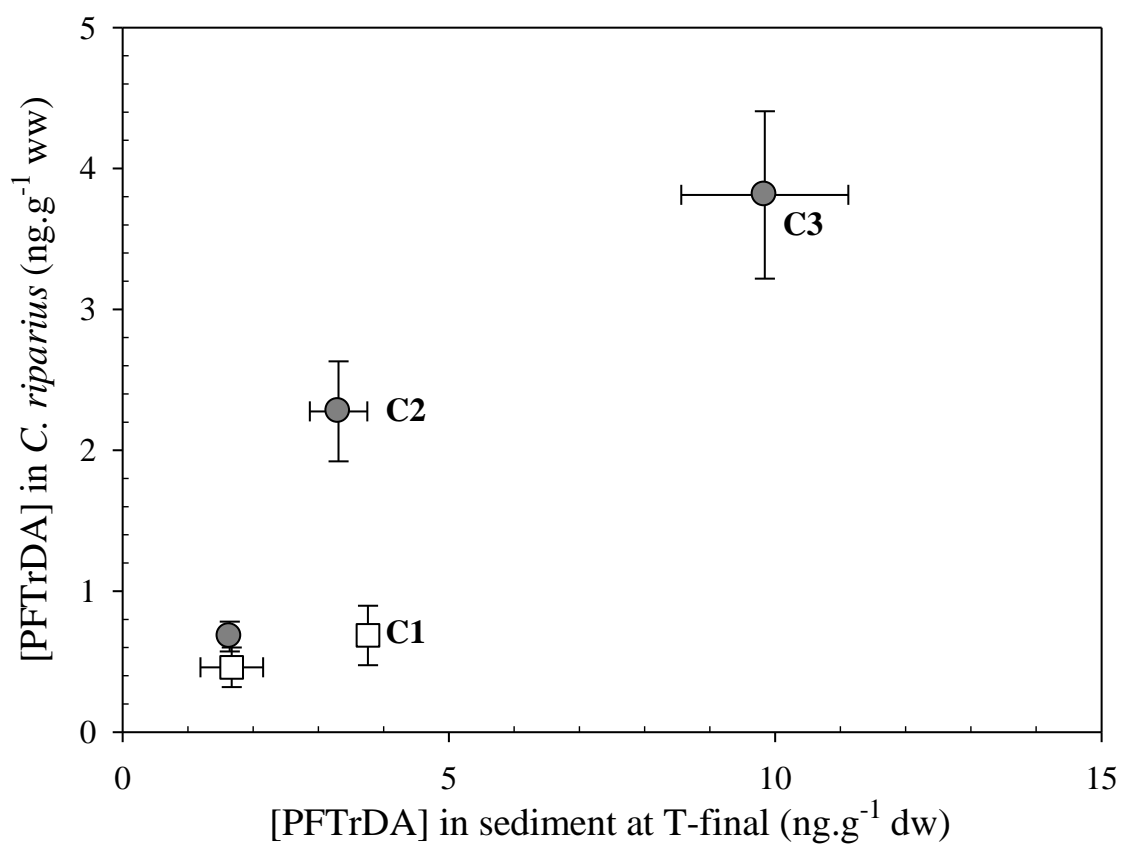

Nevertheless, the BSAFs exp $_{\text {r }}$ resulting from the different exposure conditions (Table 1) did not differ much, unlike what should have occurred in case of concentration dependency, where the BSAF should decrease while the $f_{o c}$ adjusted PFTrDA sediment concentrations increase. Nevertheless the $B S A F_{\text {exp }}$ resulting from the $\mathrm{C} 1$ experiment was obtained after a reduced exposure time, and might thus be underestimated.

\begin{tabular}{|l|l|c|c|c|}
\hline Experiments & Type & $\begin{array}{c}\text { Sediment organic } \\
\text { matter }\left(\mathrm{ng}_{\mathrm{oc}} \cdot \mathrm{g}^{-1} \mathrm{dw}\right)\end{array}$ & $\begin{array}{c}\text { Chironomids } \\
\left({\left.\mathrm{ng} . \mathrm{g}^{-1} \mathrm{ww}\right)}\right.\end{array}$ & $B S A F_{\text {exp }}$ \\
\hline Accumulation phase of the & Field & $65.92 \pm 1.79$ & $0.460 \pm 0.141$ & $0.007 \pm 0.0039$ \\
\hline
\end{tabular}


292

293

294

295

296

297

298

299

300

301

302

303

304

\begin{tabular}{|l|c|c|}
\hline Hypotheses & $\boldsymbol{k}_{\boldsymbol{u}}\left(\mathbf{g}_{\left.\mathrm{oc} \cdot \mathbf{g}_{\mathrm{ww}} \cdot \mathbf{h}^{-\mathbf{1}}\right)}\right.$ & $\boldsymbol{k}_{\boldsymbol{e}}\left(\mathbf{h}^{\mathbf{- 1}}\right)$ \\
\hline $\mathrm{H} 1$ & $0.013 \pm 0.008$ & $0.032 \pm 0.009$ \\
\hline $\mathrm{H} 2$ & $0.00077 \pm 7.5^{*} 10^{-5}$ & $0.0098 \pm 0.0042$ \\
\hline
\end{tabular}

305

306 resulting $B S A F_{\text {exp }}$ FOSA.

\subsection{Model outcomes} observed data.

\begin{tabular}{|l|l|c|c|c|}
\cline { 2 - 5 } elimination test & C1 & $168.61 \pm 4.04$ & $0.686 \pm 0.211$ & $0.004 \pm 0.0023$ \\
\hline \hline \multirow{3}{*}{ Accumulation test } & Field & $57.67 \pm 7.44$ & $0.678 \pm 0.106$ & $0.012 \pm 0.0007$ \\
\cline { 2 - 5 } & $\mathrm{C} 2$ & $153.95 \pm 20.47$ & $2.276 \pm 0.355$ & $0.015 \pm 0.0007$ \\
\cline { 2 - 5 } & $\mathrm{C} 3$ & $457.67 \pm 59.53$ & $3.812 \pm 0.594$ & $0.008 \pm 0.0004$ \\
\hline
\end{tabular}

Table 1 - PFTrDA concentrations in sediment organic matter and chironomids at $\mathrm{T}_{\text {final }}$ and

$B S A F_{\text {exp }}$ calculated for PFUnDA, PFOS and FOSA are recorded in SI, Table S8; they are in the same range as for PFTrDA, between $0.006-0.007$ for PFUnDA and $0.013-0.022$ for

The model parameters $\left(k_{u}, k_{e}, r\right.$ and $\mathrm{C}_{50}$ for PFTrDA in the case of $\mathrm{H} 1 ; k_{u}, k_{e}$ and $r$ for PFTrDA in the case of $\mathrm{H} 2$ ) were adjusted simultaneously on the basis of all results in order to obtain the best fit to the data by minimizing the weighed least squares between simulated and

The final uptake and elimination rates for PFTrDA are presented in Table 2. There was much better agreement between observed and simulated data for $\mathrm{H} 1$ (adjusted $\mathrm{R}^{2}$ 0.978, distance 1.279; Figure 3-A) than for H2 (adjusted $\mathrm{R}^{2}$ 0.655, distance 13.919; Figure 3-B).

Table 2 - Optimized uptake and depuration constants for PFTrDA.

Growth curves displayed in Figure 3-A and B (right-hand panels, fitted simultaneously with accumulation data) are essentially identical, as they rely on the same data. Slopes (growth rates) did not differ between the experiments, and between field and spiked sediments. 

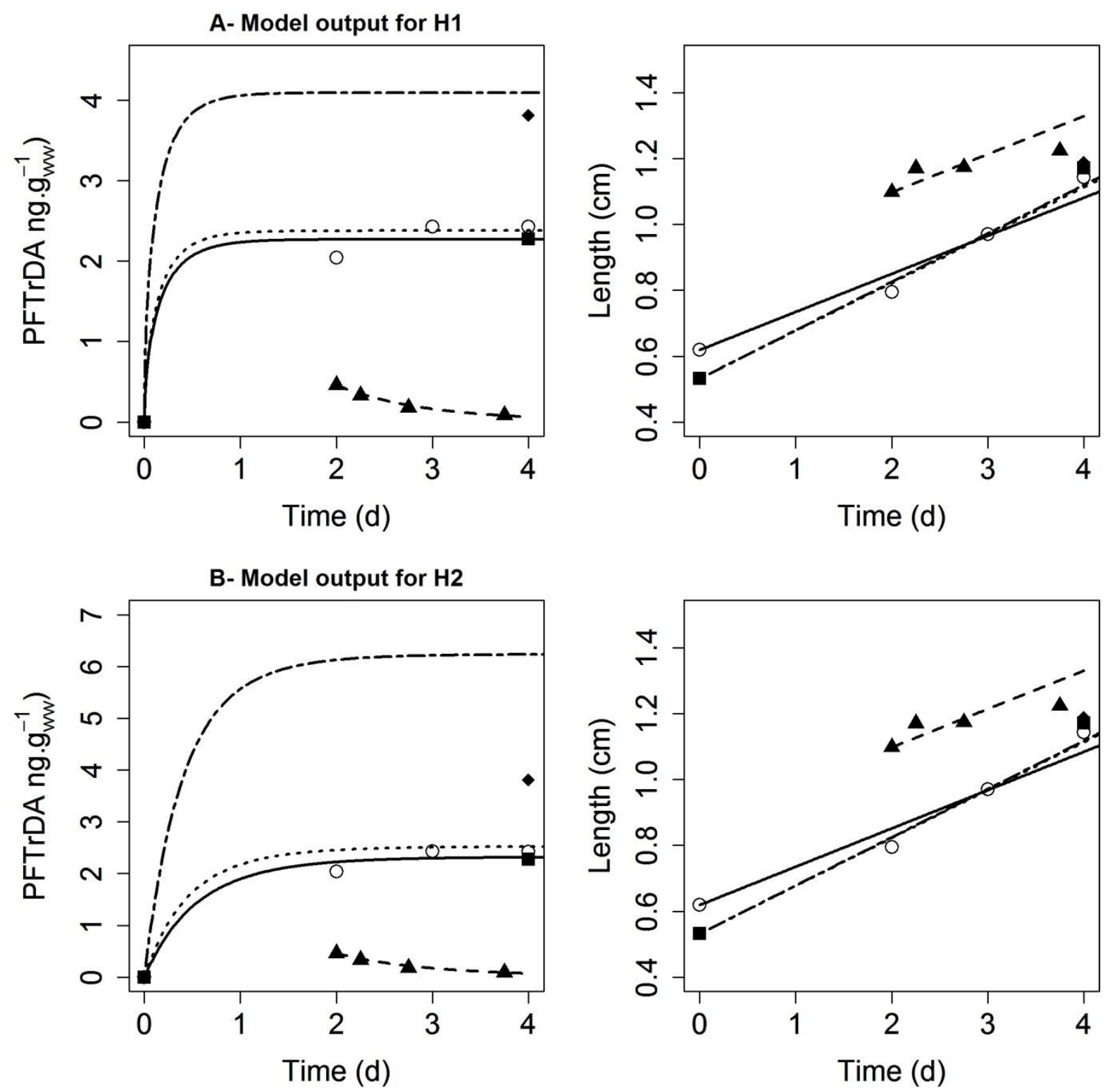

Figure 3 - Observed (symbols) and simulated (lines) PFTrDA concentrations (left hand

312 models (square/solid line: field; open dots/dotted line: C2; diamonds/sash-dot line: C3;

313 triangle/dash line: depuration phase).

314 PFTrDA half-life $\left(\mathrm{T}_{1 / 2}\right)$ on the basis of model $\mathrm{H} 1$ was 0.65 day.

\section{Discussion}

5.1. Sediment spiking

The sediment contamination profile at the sampling site is rather unusual, with PFTrDA 
contributing up to $36 \%$ to the sum of PFAS concentrations (Munoz et al., 2015), and reaching concentrations as high as $1.67 \pm 0.48 \mathrm{ng} \cdot \mathrm{g}^{-1} \mathrm{dw}$, which is comparable to Zushi et al. (2010). These authors measured this compound at $1.2 \mathrm{ng} \cdot \mathrm{g}^{-1}(\mathrm{dw})$ in Tokyo Bay sediment. Only a few other studies looked for this chemical (e.g. Zhao et al., 2015), and generally found lower concentrations than in this study. While it is therefore very difficult to confirm whether or not the spiking schedule was realistic, we considered that this was not a significant concern, given that the motivation for spiking was to determine whether or not concentration dependency occurs.

\subsection{Uptake and elimination kinetics}

The comparison of model performances for the two hypotheses shows a much better fit to experimental data for H1. The discussion about uptake and elimination kinetics is accordingly focused on $\mathrm{H} 1$ model outcomes. PFTrDA elimination by chironomids is quick even when adjusting for growth; indeed, the elimination constant equaled $0.032( \pm 0.009) \mathrm{h}^{-1}$ when calculated under the $\mathrm{H} 1$ hypothesis, with simultaneous optimization of both $k_{u}$ and $k_{e}$ (Table 2). This $k_{e}$ value is very similar to the $k_{e}$ value determined in our previous study (Bertin et al., 2014) using a partition model with a correction for growth, i.e. $0.03 \pm 0.01 \mathrm{~h}^{-1}$. Conversely, the $k_{u}$ value derived under the H1 hypothesis is about one order of magnitude greater than the $k_{u}$ derived previously $\left(0.0015 \mathrm{~g}_{\mathrm{oc}} \cdot \mathrm{g}_{\mathrm{ww}} \cdot \mathrm{h}^{-1}\right.$; Bertin et al., 2014), emphasizing the impact of model choice. However, in the present study, the proposed model takes into account the growth dilution for both uptake and elimination phases, with the length of the organisms introduced in each term of the model equation (Eq. 4). In addition, $k_{u}$ and $k_{e}$ were estimated from the same experimental data set, and estimated together. The $k_{u}$ and $k_{e}$ obtained in the present study under the concentration-dependency hypothesis are therefore more reliable than those calculated under a passive diffusion hypothesis on the basis of the accumulation phase only, or separately for two phases. Meanwhile, the BSAF values of $\left(B S A F_{\text {exp }}\right.$, Table 1) did not 
343

344

345

346

347

348

349

350

351

352

353

354

355

356

357

358

359

360

361

362

363

364

365

support the concentration-dependency hypothesis. The steady state might not be reached after

2 days of exposure, and the growth dilution is not taken into account for the $B S A F_{\text {exp }}$ calculation, which may explain why BSAFs did not follow the expected pattern.

Our experimental results did not allow for testing the concentration-dependency hypothesis for other PPFASs, such as PFUnDA or PFOS, nor to derive kinetic BSAFs by solving analytically Eq. 2, due to the growth dilution term. Overall, these BSAFs were low, confirming some field evidence (Babut et al., 2017) that chironomids would not be a significant source of PFTrDA and other PFCAs to their predators, e.g. fish.

\section{Conclusion}

The models tested herein are advantageous in that they simultaneously optimize the uptake and elimination rates while accounting for chironomid growth rate, in contrast to other studies that calculated the uptake and elimination rates from two different models (Higgins et al., 2007; Higgins et al., 2009; Van Geest et al., 2011).

Reliable experimental elimination constants $\left(k_{e}\right)$ were obtained for chironomids exposed to a field sediment contaminated by a PFAS mixture (PFTrDA, PFUnDA, and to a lesser extent PFOS, FOSA). Measured PFTrDA concentrations accumulated in chironomid tissues did not increase proportionally to their increase in sediment, but the resulting experimental BSAFs did not vary much. Nevertheless, bioaccumulation modeling with a simultaneous optimization of uptake and elimination rates consistently supported the hypothesis of concentrationdependency for this compound and yielded reliable uptake and elimination rates. Similar findings were reported by for shorter chain PFCAs (PFOA, PFNA, PFDA) in the green mussel (Perna viridis) (Liu et al., 2011), suggesting that concentration dependency could be a rather general uptake mechanism for long chain PFCAs or PFSAs. 


\section{Acknowledgements}

This study was supported by the Rhone-Mediterranean and Corsica Water Agency and the Rhone-Alpes Region within the Rhone ecological restoration plan. The Aquitaine Region and the European Union [CPER A2E project] are acknowledged for their financial support. This study also benefitted from grants of the French National Research Agency (ANR) as part of the Investments for the future Program, within the Cluster of Excellence COTE [ANR-10LABX-45]. We thank Linda Northrup (English Solutions, Voiron, France) for copyediting the text.

\section{References}

Ahrens, L., et al., 2009. Partitioning Behavior of Per- and Polyfluoroalkyl Compounds between Pore Water and Sediment in Two Sediment Cores from Tokyo Bay, Japan. Environmental Science \& Technology. 43, 6969-6975.

Ankley, G. T., 1992. Bioaccumulation of PCBs from sediments by oligochaetes and fishes: comparison of laboratory and field studies. Canadian Journal of Fisheries \& Aquatic Sciences. 49, 20802085.

Babut, M., et al., 2017. Per- and poly-fluoroalkyl compounds in freshwater fish from the Rhône River: influence of fish size, diet, prey contamination and biotransformation. Science of the Total Environment. 605-606, 38-47.

Bao, J., et al., 2009. Perfluorinated compounds in sediments from the Daliao River system of northeast China. Chemosphere. 77, 652-657.

Bao, J., et al., 2010. Perfluorinated compounds in urban river sediments from Guangzhou and Shanghai of China. Chemosphere. 80, 123-130.

Bertin, D., et al., 2014. Bioaccumulation of perfluoralkyl compounds in midge (Chironomus riparius) larvae exposed to sediment. Environmental Pollution. 189, 27-34.

Bertin, D., et al., 2016. Potential exposure routes and accumulation kinetics for poly- and perfluorinated alkyl compounds for a freshwater amphipod: Gammarus spp. (Crustacea). Chemosphere. 155, 380-387.

Bhhatarai, B., Gramatica, P., 2011. Prediction of Aqueous Solubility, Vapor Pressure and Critical Micelle Concentration for Aquatic Partitioning of Perfluorinated Chemicals. Environmental Science \& Technology. 45, 8120-8128.

Burkhard, L. P., et al., 2012. Comparing laboratory- and field-measured biota-sediment accumulation factors. Integrated Environmental Assessment and Management. 8, 32-41.

Dauchy, X., et al., 2012. Relationship Between Industrial Discharges and Contamination of Raw Water Resources by Perfluorinated Compounds. Part I: Case Study of a Fluoropolymer Manufacturing Plant. Bulletin of Environmental Contamination and Toxicology. 89, 525-530.

Ferrari, B. J. D., et al., 2014. Bioaccumulation kinetics and effects of sediment-bound contaminants on chironomids in deep waters: New insights using a low-disturbance in situ system. Environmental Technology (United Kingdom). 35, 456-469.

Greaves, A. K., et al., 2013. Brain region distribution and patterns of bioaccumulative perfluoroalkyl carboxylates and sulfonates in east greenland polar bears (Ursus maritimus). Environmental 
Toxicology and Chemistry. 32, 713-722.

Higgins, C. P., et al., 2005. Quantitative determination of perfluorochemicals in sediments and domestic sludge. Environmental Science and Technology. 39, 3946-3956.

Higgins, C. P., et al., 2007. Bioaccumulation of perfluorochemicals in sediments by the aquatic oligochaete Lumbriculus variegatus. Environmental Science and Technology. 41, 4600-4606.

Higgins, C. P., et al., 2009. Bioaccumulation of triclocarban in Lumbriculus variegatus. Environmental Toxicology and Chemistry. 28, 2580-2586.

Houde, M., et al., 2011. Monitoring of Perfluorinated Compounds in Aquatic Biota: An Updated Review. Environmental Science \& Technology. 45, 7962-7973.

Houde, M., et al., 2006. Biological monitoring of polyfluoroalkyl substances: A review. Environmental Science and Technology. 40, 3463-3473.

Labadie, P., Chevreuil, M., 2011. Partitioning behaviour of perfluorinated alkyl contaminants between water, sediment and fish in the Orge River (nearby Paris, France). Environmental Pollution. 159, 391-397.

Lasier, P. J., et al., 2011. Perfluorinated chemicals in surface waters and sediments from northwest Georgia, USA, and their bioaccumulation in Lumbriculus variegatus. Environmental Toxicology and Chemistry. 30, 2194-2201.

Liu, C., et al., 2011. Novel Perspectives on the Bioaccumulation of PFCs - the Concentration Dependency. Environmental Science \& Technology. 45, 9758-9764.

Martin, J. W., et al., 2004. Perfluoroalkyl contaminants in a food web from lake Ontario. Environmental Science \& Technology. 38, 5379-5385.

Munoz, G., et al., 2015. Spatial distribution and partitioning behavior of selected poly- and perfluoroalkyl substances in freshwater ecosystems: A French nationwide survey. Science of The Total Environment. 517, 48-56.

Myers, A. L., et al., 2012. Fate, distribution, and contrasting temporal trends of perfluoroalkyl substances (PFASs) in Lake Ontario, Canada. Environment International. 44, 92-99.

Péry, A. R. R., et al., 2002. A modeling approach to link food availability, growth, emergence, and reproduction for the midge Chironomus riparius. Environmental Toxicology and Chemistry. 21, 2507-2513.

Prevedouros, K., et al., 2006. Sources, fate and transport of perfluorocarboxylates. Environmental Science and Technology. 40, 32-44.

Prosser, R. S., et al., 2016. Bioaccumulation of perfluorinated carboxylates and sulfonates and polychlorinated biphenyls in laboratory-cultured Hexagenia spp., Lumbriculus variegatus and Pimephales promelas from field-collected sediments. Science of the Total Environment. 543, 715-726.

R-Core-team, R: A language and environment for statistical computing. R Foundation for Statistical Computing. In: R. F. f. S. Computing, (Ed.), Vienna (Austria), 2012.

Reiner, J. L., et al., 2012. Determination of perfluorinated alkyl acid concentrations in biological standard reference materials. Analytical and Bioanalytical Chemistry. 1-10.

Van Geest, J. L., et al., 2011. Accumulation and Depuration of Polychlorinated Biphenyls from FieldCollected Sediment in Three Freshwater Organisms. Environmental Science \& Technology. 45, 7011-7018.

Zhao, Z., et al., 2015. Spatial distribution of perfluoroalkyl acids in surface sediments of the German Bight, North Sea. Science of the Total Environment. 511, 145-152.

Zushi, Y., et al., 2010. Time trends of perfluorinated compounds from the sediment core of Tokyo Bay, Japan (1950s-2004). Environmental Pollution. 158, 756-763. 